\title{
Usability of a Color Selection Tool on Mobile Devices for Non-Designers
}

\section{Ashraf Qahman, Chui Yin Wong, Muhammad Hussin}

To Link this Article: http://dx.doi.org/10.6007/IJARBSS/v11-i3/9087

DOI:10.6007/IJARBSS/v11-i3/9087

Received: 04 January 2021, Revised: 28 January 2021, Accepted: 18 February 2021

Published Online: 26 March 2021

In-Text Citation: (Qahman et al., 2021)

To Cite this Article: Qahman, A., Wong, C. Y., \& Hussin, M. (2021). Usability of a Color Selection Tool on Mobile Devices for Non-Designers. International Journal of Academic Research in Business and Social Sciences, 11(3), 967-974.

Copyright: (c) 2021 The Author(s)

Published by Human Resource Management Academic Research Society (www.hrmars.com)

This article is published under the Creative Commons Attribution (CC BY 4.0) license. Anyone may reproduce, distribute, translate and create derivative works of this article (for both commercial and non-commercial purposes), subject to full attribution to the original publication and authors. The full terms of this license may be seen

at: http://creativecommons.org/licences/by/4.0/legalcode

Vol. 11, No. 3, 2021, Pg. 967 - 974

http://hrmars.com/index.php/pages/detail/IJARBSS

JOURNAL HOMEPAGE

Full Terms \& Conditions of access and use can be found at http://hrmars.com/index.php/pages/detail/publication-ethics 


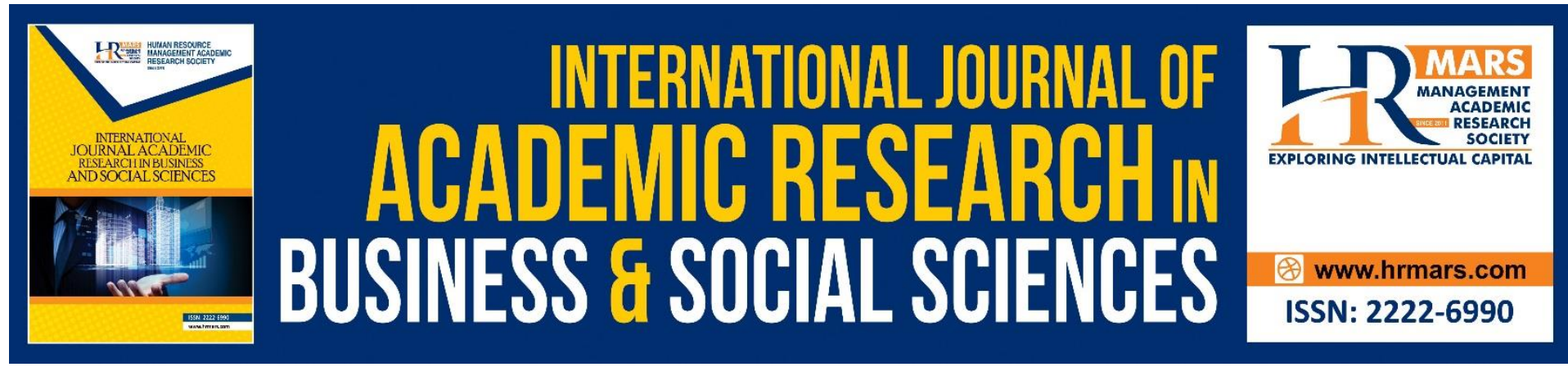

\title{
Usability of a Color Selection Tool on Mobile Devices for Non-Designers
}

\author{
Ashraf Qahman, Chui Yin Wong, Muhammad Hussin \\ Faculty of Creative Multimedia, Multimedia University, Malaysia \\ Faculty of Education, Universiti Kebangsaan Malaysia \\ Email: ashqahman@gmail.com,cywong@mm.edu.my,muhsin@ukm.edu.my
}

\begin{abstract}
Non-designers, who are not trained in arts and design backgrounds, are generally lack of knowledge on color and design principles. Thus, some may have less aesthetical sense and color appreciation for interior design. This paper aims to investigate ease of use and usability of color selection tool for non-designers, who are not familiar to apply color and mood setting on interior design. A usability evaluation was conducted with 30 participants. The result shows an average score of 2.63/5.0, revealing poor usability of using a Paint Tester Application for non-designers. Therefore, it is important for mobile apps developers to evaluate the usability components and user acceptance for improved apps development. Future studies will encompass a comparative analysis of different color selection tools for non-designers.
\end{abstract}

Keywords: Usability, Color Selection Tool, Non-designers, Mobile App, Interior Design

\section{Introduction}

Most of the interior architectural designs in ancient time do not encompass an understanding of color and its theories, where colors are generally used according to an artist's passions and personal appreciation on color indications and its symbols. Additionally, the artists also took into account their association with religious belief and popular heritage of each region that beared the same customs and traditions (Huppatz, 2012). Meanwhile, color plays a vital role in the field of interior spaces, it can highlight the elements of furniture and its relationship with the contents of the formation for the space, floors, ceilings and walls. Moreover, color also influence our mood and perception in all aspects of our activities in public and private life (van der Voordt, Bakker, \& de Boon, 2017). For example, color is one of the most important pillars in the creation of harmonious color schemes as well as it represents an important challenge in visual design (Hu, Pan, Zhang, Chen, Yang, \& Chen, 2014). An American educator, Rudolf Arnheim, stated 'color can reflect human emotions faithfully, and this is an irrefutable fact' (Na \& Suk, 2014).

\section{Problem Statement}

Interior design is defined as the art of treating places and empty spaces through the use of all aesthetic design elements that help to work and spend time in those places, and the product of a set of creative ideas and planning based on the specifications of places or empty 
spaces to be filled and cheerful with its color design (Goldstein \& Goldstein, 2017). In addition, many recent studies have shown that colors have a great influence on our emotions. For instance, Birren (2006) stated that color is one of the effective factors in a space, which influences the way individuals express their emotions. As a result, some colors are denoted as positive feelings, that express comfort, love, happiness and joy; while other colors arouse negative feelings of anxiety, confusion, sadness and hatred, in which bring obvious impact on individual's mood and health. Likewise, Liu and Luo (2016) claimed that, there have been many differences in the development of a fundamental basis for the psychological implications of the colors. Moreover, there have been some discrepancies in the interpretation of the implications of one color between a period of time and the other, in addition to the different psychological effects of colors for human civilizations throughout the ages.

Previous literature had mentioned the use of colour in different settings such as colour and animation preference for automated vehicles and pedestrians (Dey, Habibovic, Pfleging, Martens, \& Terken, 2020), colour and lighting in hospital design (Dalke, Little, Niemann, Camgoz, Steadman, Hill, \& Stoll, 2006), Colour in Interior Design (Haller, 2017), colour thinking in the interior-design process (Attiah, 2016). However, there are limited studies depicting colour use in interior design for non-designer. As a result, with the prevalence of using digital tools and computer equipment in interior design and architectural setting, three dimensional (3D) software tools have become a new and distinctive trend recently, but most of these tools require advanced computer skills and 3D experience in order to use them in the right way (Miyai \& Yamaguchi, 2016; Xing \& Wang, 2019).

Therefore, it is necessary for non-designers to be able to find uncomplicated software tools to opt for colors selection to get an overall impression of own interior spaces. In addition, most people are living in the era of D.I.Y (do-it-yourself) and there may be economic reasons to prevent the hiring of a specialist to do the task. Consequently, the color can be regarded as one of the most important reasons for the success or failure of a design. So, it is always advisable to be careful when choosing colors for an interior design as the color selection can provoke emotion and it is also one of the challenges faced by non-designers for interior design. Therefore, one should take into account several factors when choosing colors for the nature of a home decor and room design.

\section{Objective of the Study}

- To evaluate the total perception of the usability of a color selection tool for nondesigners in selecting colors and apply them on interior spaces,

- To explore the usability score of Paint Tester App for non-designers.

\section{Literature Review}

\section{Color Theory and its Application on Interior Design}

Color theory is based on a set of concepts related to color and its design and applied uses, which are related to the concept of human perception, philosophical vision, intellectual tendencies and all related physiological and psychological aspects (Rosen \& Purinton, 2004). Color wheel is categorized into primary, secondary and tertiary colors. Primary colors are a group of colors, where blending creates a spectrum of other colors. For human applications, three colors are often used. The colors commonly used are red, green and blue (RGB). Secondary colors are colors derived from primary colors, in the second half of the nineteenth century, the colors of the Impressionists were divided into warm colors and cold colors, 
according to the impression of the gaze of the beholder. Whereas, blue and its derivatives are of cold colors, red and its derivatives of colors are of warm colors (Da Pos \& Albertazzi, 2010). According to Sherman and Clore, the white and black colors represent the neutral state of the colors between warm and cold (Sherman \& Clore, 2009).

As the color is an essential element of design because it has a psychological and emotional role as well as it directs the human towards a positive or negative reaction to colors, the sense of warm color gives us a beautiful feeling, and the sense of cold color gives us a sense of calm (van der Voordt, Bakker, \& de Boon, 2017). Therefore, it exposes the most important consideration in the simulation of this feeling in a deliberate manner through the design. Thus, the internal spaces of the hospital rooms, classrooms, restaurants and offices choose different colors to suit the function of each space, so that they play a role in achieving the desired effect in the behavior and mood of the people who are in those spaces (Kaya \& Crosby, 2005).

\section{Usability Studies}

Usability can be defined as the extent of which a system, product, or service is used by limited users to achieve specific objectives effectively, efficiently and satisfactorily from the user and within a specific context of use (Usability First, 2015). The key to developing a highly scalable tool is the application of user-centered design. As part of the user-centered design, the tool must be tested early through the various methods of usability testing that help content development, information Architecture, visual and interactive design, and user satisfaction as well (Usability First, 2015).

There are many methods of conducting usability studies. One is user-based evaluation by engaging the users to determine usability issues. The purpose of these methods is to record the performance of users through different forms such as the observation and measuring the satisfaction of users based on interviews and questions to measure the interaction with the user interface, where the researcher through this study to use this way to reach the results to assess the usability (Bevan, Carter, \& Harker, 2015). For this study, we refer to System Usability Scale (SUS) and additional sample usability post-test questions related to mobile apps (mHIMSS, 2012) for usability evaluation study. SUS scale is a reliable tool for measuring usability, it is a ten-question questionnaire to be answered according to 5 Likert-scales (Strongly disagree, Disagree, Neither disagree nor agree, Agree, Strongly agree). This test was developed by Brooke John in 1986 where it can be used to evaluate products or services. The SUS feature is available and fast and is one of the least expensive and most effective ways to test the usability and detection of defects and effectively explains whether the product is usable or not (Lewis \& Sauro, 2018). For mobile app-related questions, we refer to the usability post-test questions (mHIMSS, 2012).

\section{Methodology}

This paper is part of a larger study on usability of color selection tools for nondesigners. The focus of this paper is to depict the result of a usability study for a color selection tool for non-designers. We had conducted a usability evaluation study, which comprised of quantitative study (questionnaire) and qualitative (interview and observation). According to Nielsen (2001), most of the usability of problems can be found from 5 participants. During the user recruitment process, we had set the inclusion and exclusion criteria. The inclusion criteria are the potential users from any backgrounds, who are interested to explore using a color selection tool for interior design. We exclude those educational background or job profession 
related to arts and design fields because they are usually well-versed in color theory and its application. All the participants were required to sign a consent form to record the session without revealing their identity. As all of them have not used the apps before, they are allowed to navigate around to explore briefly for 5 minutes. They were asked to think aloud about their thoughts when they were interacting with the tasks.

\section{Task Design and Usability Evaluation Instrument}

Four tasks were selected for the usability study, which are: (1) Recognize the application icon. (2) Select at least two different colors from the application. (3) Match the two colors on two different walls in a room. (4) Save the project file and share the final work online.

The items selection in the usability evaluation instrument were based on mHIMSS App Usability Work Group (2012) for a mobile app. We customized it accordingly to suit the context of this study.

\section{Location}

The venue for the usability study was conducted at iSpace Hall at the Faculty of Creative Multimedia, Multimedia University in Malaysia. The participants were required to use the Paint Tester app to apply the color selection features on two adjacent walls with yellow and blue colors. These two colors were chosen due to its easily distinguished and recognizable for visibility reason.

\section{Color Selection Tool}

We had identified and filtered color-related applications from Google Play Store, Apple App Store and other open access resource with the keywords of 'colour', 'color', 'paint your home', 'test colour', and 'visualise colour'. We finalized by reviewing the 10 relevant mobile applications (apps), and found that they all shared the similar goal of helping nondesigners to select color for space and interior design. The differences are the features, and usability of the color selection tool. We had narrowed down three final mobile apps for the usability study. However, for the context of this paper, the color selection tool is Paint Tester (Luminant Software, 2019) for Android OS smartphone (Figure 1).
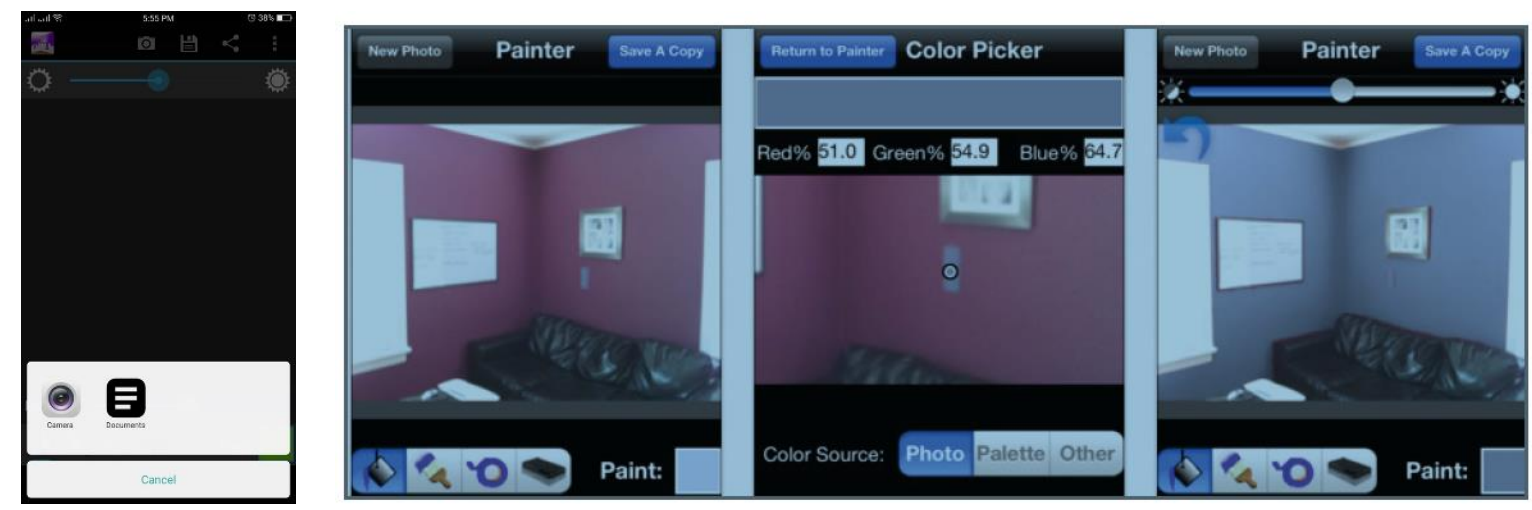

Figure 1. Homepage (left), and screenshots of Paint tester app.

\section{Results and Discussion}

This section reports the result and discussion of the usability study. 


\section{Demographic Profile}

There were 30 participants, which comprised of 19 males (63.33\%) and 11 females (36.67\%). All participants were non-designers, and they did not receive any formal arts or design educational backgrounds. Their previous major of studies were categorized into Information Technology (IT) ( $n=6,20.00 \%)$, Political Science $(n=5,16.67 \%)$, and other majors except arts and design ( $n=10,33.33 \%)$. They also did not have any prior experience using the Paint Tester app before.

\section{Usability Results of Paint Tester App}

In order to measure the internal consistency and validity of the items presented under each construct in the questionnaire, reliability analysis was conducted. Cronbach's Alpha reliability coefficients were calculated to determine the consistency. According to Kline (2013), Cronbach's Alpha value that falls within the range of 0.70-0.90 is considered as high reliability. The result shows that the Cronbach's Alpha for Paint Tester app is 0.783 , which means the scale demonstrates a high internal consistency. This validates the constructs for their consistency and none of the 20 items in the questionnaire were excluded for further analysis. Table 1 below shows the result of participants' usability score of Paint Tester app. The score was based on a five-point Likert scale for the range of ' 1 (strongly disagree) to 5 (strongly agree)'.

Table 1

Usability Score of Paint Tester App

\begin{tabular}{|l|l|l|l|}
\hline No & Items & Mean (1 -5) & $\begin{array}{l}\text { Standard } \\
\text { Deviation (SD) }\end{array}$ \\
\hline 1 & App icon is attractive & 3.067 & 0.944 \\
\hline 2 & App icon reflects the function of the app & 3.000 & 0.983 \\
\hline 3 & $\begin{array}{l}\text { The welcome interface gives a good initial impression of the } \\
\text { app }\end{array}$ & 2.633 & 1.098 \\
\hline 4 & The welcoming interface has an aesthetic theme. & 2.533 & 1.008 \\
\hline 5 & The main interface is comprehensive to what the app offers. & 2.433 & 1.073 \\
\hline 6 & Moving from one section to another was easy. & 2.700 & 0.952 \\
\hline 7 & Fonts used are readable. & 2.400 & 0.969 \\
\hline 8 & The fonts used are clear. & 2.633 & 1.098 \\
\hline 9 & The colours used are attractive. & 2.500 & 1.137 \\
\hline 10 & The buttons change their status when clicked. & 2.533 & 0.860 \\
\hline 11 & The app responds quickly. & 2.367 & 0.809 \\
\hline 12 & Accessing the camera in the app was easy. & 2.667 & 0.884 \\
\hline 13 & The colour palette in the app was clearly visible. & 2.700 & 0.916 \\
\hline 14 & No complications in colour selection. & 2.767 & 1.135 \\
\hline 15 & It was not difficult to fill the spaces with colours. & 2.600 & 1.191 \\
\hline 16 & The app is able to identify the boundaries. & 2.700 & 1.149 \\
\hline 17 & There is no complexity in saving the project. & 3.166 & 1.234 \\
\hline 18 & Final work sharing with others is available on the app. & 2.400 & 1.365 \\
\hline 19 & Using the app was not frustrating. & 2.200 & 1.215 \\
\hline 20 & I'm going to use the app later. & 2.633 & 1.184 \\
\hline & Total Mean Score & 2.631 & 1.060 \\
\hline
\end{tabular}


In general, the participants spent around 10 to 15 minutes navigating and interacting with the app. The usability result shows that the total mean score is 2.63 out of 5.00 scores, which is considered at the borderline of poor usability. The highest score is 3.17 out of 5.0 for the item of 'there is no complexity in saving the project'. This indicates that the participants were quite satisfied with the feature of saving the project file using Paint Tester app. On the contrary, the lowest score is the item of 'using the app was not frustrating' (2.20). This also reflected in the Review section for Paint Tester App at Google App Store, where the users' review score was 2.9 out of 5.0. In general, users commented that the feature of selecting the color is not so straight forward, the button did not update the status after clicking, and difficult to fill the space with color and apply on the wall in the room. Thus, this process yielded user frustration and impacted poor user experience of using Paint Tester app. The researcher and the participants' comments during and after the completion of the user experience noticed that they encountered difficulty in using the application as most of the tasks were not completed, nor did they like the user interface in terms of icons, fonts and aesthetics in general. These comments coincided with the statistical results which made the application least acceptance. In a nutshell, Paint Tester fails to fulfill users' requirement, and there is a mismatched of user expectation and mobile app design. This yields to poor user experience and users generally will not consider using this mobile app.

\section{Conclusion}

Generally, it is getting more and more popular for everybody to use a color selection tool for interior design or home decoration. Users from various backgrounds with or without art and design skills can just easily refer to either Google App Store or Apple App Store to download and use a color selection tool. In order to cater for all smartphone users' needs, it is important for mobile app designers and smartphone user interface designers to ensure user experience and ease of use for the mobile app design. The result shows that Paint Tester was not the favorite color selection tool for non-designers due to its poor usability. Thus, the developers and designers need to take into consideration to improve their user experience of the app. As stated earlier, this paper is part of a larger usability study. Future study will compare and analyse three different color selection tools for non-designers on interior design.

\section{Acknowledgments}

The researchers would like to thank the participants who volunteered to participate in this usability study.

\section{References}

Attiah, D. Y. (2016). A Constant-theoretical Sampling and Comparison Approach to Optimise Colour Thinking in the Interior-design Process. (Unpublished doctoral dissertation). University of Leeds, United Kingdom.

Bevan, N., Carter, J., \& Harker, S. (2015). ISO 9241-11 Revised: What Have We Learnt About Usability Since 1998? Lecture Notes in Computer Science, 143-151. doi:10.1007/978-3319-20901-2_13

Birren, F. (2006). Color psychology and color therapy: A factual study of the influence of color on human life. New York: University Books, Inc.

Da Pos, O., \& Albertazzi, L. (2010). It Is in the Nature of the Colours. Seeing and Perceiving, 23(1), 39-73. 
Dalke, H., Little, J., Niemann, E., Camgoz, N., Steadman, G., Hill, S., \& Stott, L. (2006). Colour and lighting in hospital design. Optics \& Laser Technology, 38(4-6), 343-365.

Dey, D., Habibovic, A., Pfleging, B., Martens, M., \& Terken, J. (2020). Color and animation preferences for a Light Band eHMI in interactions between automated vehicles and pedestrians. CHI'20: Proceedings of the $2020 \mathrm{CHI}$ Conference on Human Factors in Computing Systems (pp. 1-13). USA: ACM Press.

Goldstein, H., \& Goldstein, V. (1929). Art in everyday life. New York: The Macmillan Company.

Haller, K. (2017). Colour in interior design. In Janet Best (Ed.), Colour Design (pp. 317-348). Cambridge, MA: Woodhead Publishing Series in Textiles.

Huppatz, D. (2012). The First Interior? Reconsidering the Cave. Journal of Interior Design, 37(4), 1-8.

Hu, G., Pan, Z., Zhang, M., Chen, D., Yang, W., \& Chen, J. (2014). An interactive method for generating harmonious color schemes. Color Research \& Application, 39(1), 70-78.

Kaya, N., \& Crosby, M. (2005). Color associations with different building types: An experimental study on American college students. Color Research \& Application, 31(1), 67-71. doi:10.1002/col.20174

Kline, P. (2013). The handbook of psychological testing. New York: Routledge.

Lewis, J. R., \& Sauro, J. (2018). Item benchmark for the system usability scale. Journal of Usability Studies, 13(3), 158-167.

Liu, S., \& Luo, H. (2016). Hierarchical emotional color theme extraction. Color Research \& Application, 41(5), 513-522.

Luminant Software. (2019). Paint Tester. Retrieved on March 3, 2020 from https://luminantsoftware.com/apps/paint-tester/

Miyai, A., \& Yamaguchi, Y. (2016). New approach to camerawork skills education for 3D/S3D computer graphics animation. Computers \& Graphics, 59, 119-129.

MHIMSS. (2012). Selecting a mobile app: Evaluating the usability of medical applications. Retrieved on March 4, 2020 from http://s3.amazonaws.com/rdcmshimss/files/production/public/HIMSS guidetoappusabilityv1mHIMSS.pdf

Na, N., \& Suk, H. J. (2014). The emotional characteristics of white for applications of product color design. In J. Watada, H. Shiizuka, K.-P. Lee, T. Otani, \& Lim, C.-P. (Eds.), Industrial Applications of Affective Engineering (pp. 253-264). Germany: Springer.

Nielsen, J. (2001). Success rate: the simplest usability metric. Retrieved on February 29, 2020 from https://www.nngroup.com/articles/success-rate-the-simplest-usability-metric/

Rosen, D. E., \& Purinton, E. (2004). Website design: Viewing the web as a cognitive landscape. Journal of Business Research, 57(7), 787-794.

Sherman, G. D., \& Clore, G. L. (2009). The color of sin: White and black are perceptual symbols of moral purity and pollution. Psychological Science, 20(8), 1019-1025.

Usability First. (2015). Introduction to User-Centered Design. Retrieved on April 02, 2016 from http://www.usabilityfirst.com/aboutusability/introduction-to-user-centered-design/

van der Voordt, T., Bakker, I., \& de Boon, J. (2017). Color preferences for four different types of spaces. Facilities, 35(3/4), 155-169.

Xing, S., \& Wang, M. (2019). Practical application analysis of 3DMax in interior design. IOP Conference Series: Earth and Environmental Science (EES). Bristol, UK: IOP Publishing. 